\title{
The Mizan meta-memory and meta- concentration scale for students (MMSS): a test of its psychometric validity in a sample of university students
}

Md. Dilshad Manzar ${ }^{1}$, Abdulrhman Albougami ${ }^{1}$, Mohammed Salahuddin ${ }^{2 *}$, Peter Sony ${ }^{3}$, David Warren Spence ${ }^{4}$ and Seithikurippu R. Pandi-Perumal ${ }^{5}$

\begin{abstract}
Background: Predisposing factors for metacognitive dysfunctions are common in university students. However, there is currently no valid questionnaire instrument designed to assess metacognitive aspects including meta-memory and meta-concentration in students. To address this need, the present study investigated the psychometric validity of a brief questionnaire, the Mizan meta-memory and meta-concentration scale for students (MMSS) in university students.

Materials and methods: A cross-sectional study with simple random sampling was conducted among students $\left(n=383\right.$, age $=18-35$, body mass index $\left.=21.2 \pm 3.4 \mathrm{~kg} / \mathrm{m}^{2}\right)$ of Mizan-Tepi University, Ethiopia. MMSS, a socio-demographics questionnaire, and the Epworth sleepiness scale (ESS) were employed.

Results: No ceiling/floor effect was seen for the MMSS global and its sub-scale scores. Confirmatory factor analysis showed that a 2-Factor model had excellent fit. Both, the comparative Fit Index (CFI) and goodness of fit index were above 0.95, while both the standardized root mean square residual and root mean square error of approximation (RMSEA) were less than 0.05 , while $x^{2} / \mathrm{df}$ was less than 3 and PClose was 0.31. The 2-Factor MMSS model had adequate configural, metric, scalar, and strict invariances across gender groups as determined by a CFI $>.95, \operatorname{RMSEA}<.05, x^{2} / \mathrm{df}<3$, non-significant $\Delta x^{2}$ and/or $\Delta$ CFI $\leq .01$. Good internal consistency (Cronbach's alpha $=0.84,0.80$ and McDonald's Omega $=0.84,0.82$ ) was found for both subscales of the MMSS. No correlations between the MMSS scores and ESS score favored its divergent validity.
\end{abstract}

Conclusion: The MMSS was found to have favorable psychometric validity for assessing meta-memory and metaconcentration among university students.

Keywords: Affective disorders, Cognitive function, Consistency, Divergent validity, Factor analysis, Khat, Meta-concentration, Meta-memory, Validity

\section{Background}

The mental process of metacognition is a growing subject of neuro-psychological research, with particular relevance for the processes of teaching and learning, and thus for the education system [1]. Metacognition is defined as awareness and cognition about one's own cognitive processes [2]. Individuals' perceptions of their internal mental

\footnotetext{
* Correspondence: salahuddin.mmohammed@gmail.com

${ }^{2}$ Department of Pharmacy, College of Medicine and Health Sciences,

Mizan-Tepi University (Mizan Campus), Mizan-Aman, Ethiopia

Full list of author information is available at the end of the article
}

states, as well as their self and non-self attributions, are determined by a set of affective and cognitive skills, broadly described as meta-cognitive abilities [3]. Metacognitive problems are associated with impairments to the affected person's social functioning, which in turn decrease their quality of life as well as their ability to respond to treatment [3]. Metacognitive impairments are associated with affective disorders such as depression, stress, and anxiety [3-5]. However, all of these affective states are commonly reported to occur among university students across the world $[6,7]$. Furthermore, substance use, such as alcohol

(c) The Author(s). 2018 Open Access This article is distributed under the terms of the Creative Commons Attribution 4.0 International License (http://creativecommons.org/licenses/by/4.0/), which permits unrestricted use, distribution, and 
consumption is generally associated with metacognitive dysfunctions, and is a prevalent activity among university students in many parts of the world [8]. It was recently found that the prevalence of alcohol consumption and chewing of khat, an indigenous psychoactive substance, was, respectively, 32.3 and $27.9 \%$ among Ethiopian university students [8]. These relationships among metacognitive dysfunctions, affective disorders, and substance use that are prevalent in student populations highlight the need for a tool to screen for dysfunctions in metacognition and its aspects among university students.

Meta-memory and meta-concentration are two very important dimensions of metacognition $[9,10]$. Meta-memory and meta-concentration are associated with success in everyday functioning. Furthermore, there is an interaction effect between these two metacognitive aspects that is essential for success in daily routine activities [10]. Those with meta-cognitive and meta-memory deficits develop a protectionist approach to avoid challenging situations, thus affecting their capacity to deal with similar situations in the future, and thus having broadly detrimental effects for dealing with life problems and adjustment $[9,11]$. There is a reciprocal relationship between meta-memory and other metacognitive characteristics such as vocabulary development and comprehension [12]. Meta-cognitive instructions have intermediate and delayed effects, which can manifest in improved mathematical achievement and improved cognitive regulation among students [13]. Various studies have suggested that knowledge about meta-memory can be acquired and may directly benefit the learning process in students [14]. Metacognitive abilities related to concentration i.e., meta-concentration, is one of the most important non-intellective psychological factor which can influence students' performance, as indicated by grade point average [15]. At the present time, there is no questionnaire designed to measure these metacognitive aspects, either separately or in terms of their interactive effects, in student populations. It was thus felt that a brief, easily administered, and valid questionnaire would be of use to campus counselors, psychologists, and others. It was also felt that such a tool could help in the routine screening of the students.

We therefore investigated the literature on this subject for useful examples of instruments that could be adapted for use with students. A number of excellent psychometric instruments currently exist for diagnosing meta-memory and meta-concentration. These include commonly used questionnaires for metacognition such as the Metamemory in Adulthood (MIA) scale [16], which has 108 items, the Metacognition Questionnaire (MCQ), which has 65 items [17], and the Metacognition Questionnaire-30 (MCQ-30), which has 30 items [17]. These instruments, however, are primarily designed for use in medical or psychiatric settings, and while they tend to be exhaustively comprehensive, they can be cumbersome and time-consuming to administer. An exception to this generalization is a brief metacognition questionnaire,which was recently developed for use at the Charité - University Medicine Berlin [10]. The present investigators reviewed this questionnaire and used it as a guide for developing the questionnaire that is reported on here, although it has been modified to make it more appropriate for students. In this study, we present the psychometric properties of this adapted version of a brief meta-memory and meta-concentration questionnaire, which has been designed to suit the daily activities of university student populations.

\section{Methods}

The study presents findings of data taken (Fig. 1) from a cross-sectional study using simple random sampling method regarding psychological health and associated factors among university students carried out at the Mizan campus of the Mizan-Tepi University (MTU), Mizan-Aman, Bench Maji Zone, South Nation Nationalities Peoples Region, Ethiopia.

\section{Participants}

Three hundred and eighty-three university students with an age range of $18-35$ years and a body mass index of $21.2 \pm 3.4 \mathrm{~kg} / \mathrm{m}^{2}$ completed this study. Students with self-reported mental illness difficulties, such as a previous diagnosis of depression or psychosis that might have compromised the data quality were excluded. Similarly, those under the age of 18 years were not included because in such cases consent would have to have been obtained from their parents as well, a difficult requirement to fulfill inasmuch as many students were from remote regions of the country.

\section{Procedures}

The Institutional Ethics Committee, College of Medicine and Health Sciences, Mizan-Tepi University approved the research. Guidelines for Good Clinical Practice and the norms of the 2002 Declaration of Helsinki (DoH) were followed. Informed written consent was provided by the participants after the objective and procedures of the study were explained to them. The Mizan meta-memory and meta-concentration scale for students (MMSS), a semi-structured socio-demographics questionnaire, plus the Epworth sleepiness scale (ESS) were employed. The questionnaire packages were administered in English because participating students belonged to different linguistic groups and had differing levels of proficiency for reading Amharic. Moreover, the study participants were students of a university in Ethiopia, where the medium of instruction is English. The instruments were administered to the participants at the university premises by those members of the team of investigators who were also part of the MTU faculty. 


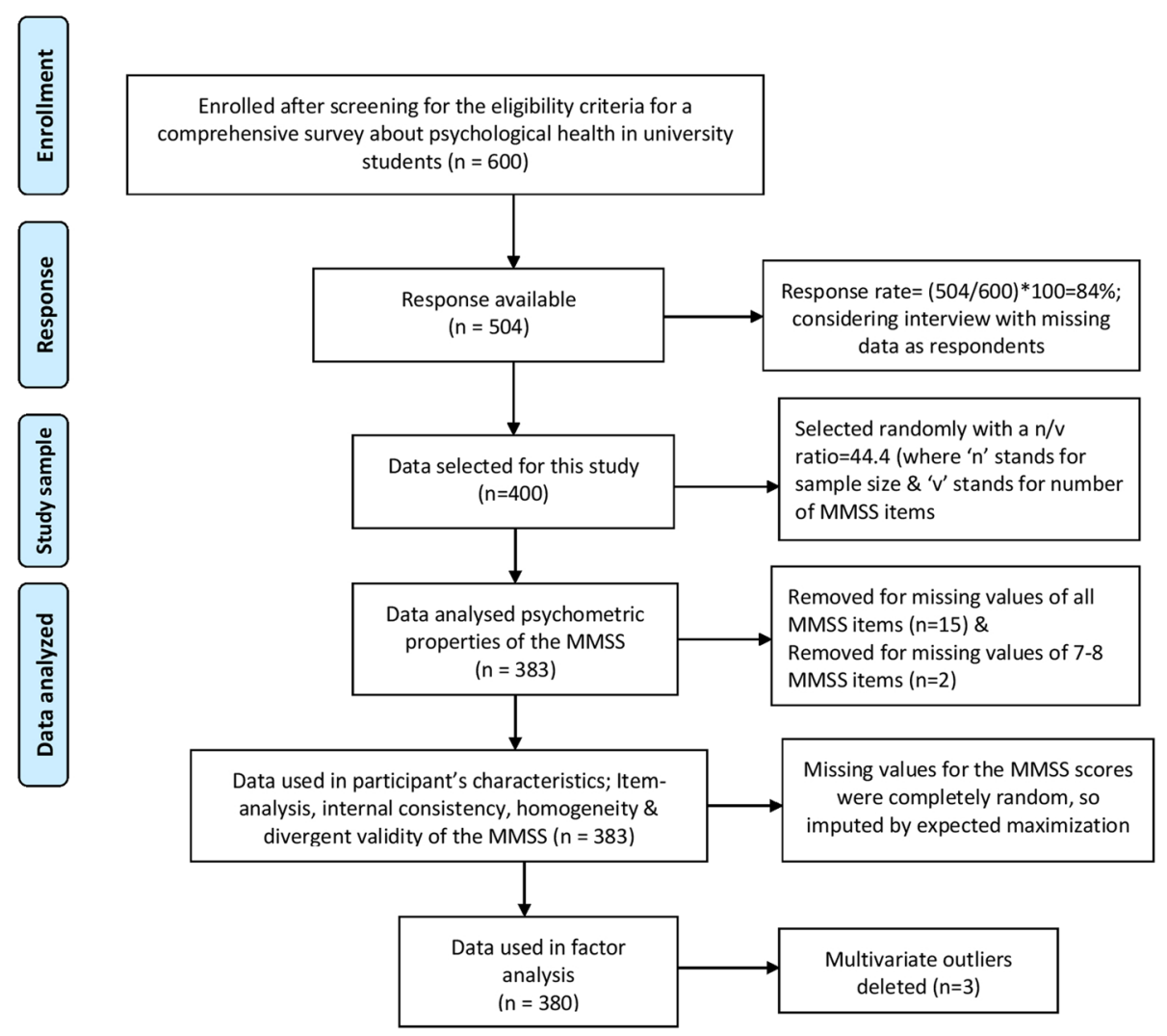

Fig. 1 Schematic of study sample

The Mizan meta-memory and meta-concentration scale for students (MMSS)

\section{Background and questionnaire conceptualization}

As a first step for developing the scale, a panel of experts was brought together to discuss the objective of constructing a new tool for assessing meta-memory and meta-concentration in the target audience of university students. Panel members, who were drawn from the fields of psychometrics, physiology, medicine, statistics, and languages, were asked to develop scale items according to several criteria. Among these criteria priority consideration was given to the scale's potential usability in survey research, response rate maximization, conciseness, and appropriateness as a preliminary screening tool. Following a detailed search of the literature which sought to gather previous experience regarding scale readability as well as comprehensibility, twelve items were generated. Some of the items were adapted from a metacognition assessment instrument developed by Klusmann and colleagues at the Department of Psychiatry, Charité - University Medicine Berlin [10]. The items measuring meta-memory were based on the questionnaire of meta-memory in adulthood developed by Dixon and colleagues [16]. The items measuring meta-concentration were based on the EURO-D, which was developed by Prince and colleagues [18]. The items of the original instrument were adapted to suit the metacognitive functions associated with the daily activities of students. None of items were reverse scored in our preliminary questionnaire.

\section{Format and content validity}

The panel of experts assessed and revised these items for relevance, comprehension and clarity. It was agreed to delete one of the items, 'I am good at reasoning, planning activities, or solving problems', after discussions because experts did not find it relevant to meta-memory and meta-concentration.

\section{Field testing}

An 11-item scale was finally developed and employed in an initial field test. This testing led to a decision to delete two items due to their significantly adverse effect on the overall internal consistency as determined by the Cronbach's alpha test. These items were, 'I have no issues of memory losses' and 'I have no difficulties related to concentration'.

\section{Final tool: MMSS}

The preliminary testing of the MMSS produced a brief questionnaire with nine items that assess two aspects of 
metacognition, i.e., meta-memory (five items) and metaconcentration (four items). The MMSS used in this study is shown in Additional file 1: Appendix I. The items are scored in the range of $1-5$, where, ' 1 ' stands for 'strongly disagree' and ' 5 ' denotes 'strongly agree'. Individual scores of the 9-items of the MMSS are linearly added to get the global score of the MMSS in the range of 9 and 45, where higher scores imply good meta-cognitive ability in areas of meta-memory and meta-concentration. Individual scores of the five items of the meta-memory subscale are linearly added to obtain the total score for this dimension. Similarly, scores for the four items of the meta-concentration subscale are added to get total score for this dimension.

\section{Epworth sleepiness scale}

The ESS is an eight item questionnaire which is used to assess daytime sleepiness [19]. These 8-items have a four-point scale, where, ' 0 ' indicates 'would never nod off', while, ' 3 ' indicates a high chance of nodding off in eight different situations encountered in daily lives [19]. The scores of individual item scores are added to get the ESS total score in the range of 0 to 24. Increasing levels of daytime sleepiness are indicated by higher ESS scores [19].

\section{Socio-demographics questionnaire}

A semi-structured socio-demographics questionnaire with nine items, one open ended and eight close ended, were used. Information concerning the respondent's age, gender, ethnicity, alcohol use, khat use, smoking, use of tea/coffee, use of other beverages such as soft drinks and other fermented/non-fermented non-alcoholic indigenous drinks and presence of chronic conditions were collected. Height and weight were taken for assessing body mass index.

\section{Statistical analysis}

Data analysis was performed by SPSS version 23.0, an add-on module called AMOS, and two plugins [20, 21]. Participants' characteristics were examined using the mean $( \pm \mathrm{SD})$, frequency, and percentage. Item analysis was performed by mean $( \pm \mathrm{SD})$, skewness, kurtosis, percentage, Spearman's item-Factor correlations, and the Cronbach's alpha (if the item were deleted). The internal consistency of the responses was assessed by the application of the Cronbach's alpha and the McDonald's Omega test. Nunnally and Bernstein have suggested that during the initial stage of research, as in the case of questionnaire development, a Cronbach's alpha of 0.70 is sufficient. However, the experimental research where emphasis is on quantitative aspect of correlation as well as the differences in mean, a Cronbach's alpha of 0.80 may be desirable [22]. The internal homogeneity and divergent construct validity were evaluated by the Spearman's correlation coefficient test.

Three multivariate outliers were identified, and hence deleted, for factor analysis following application of Mahalanobis distance testing (criterion of a $=.001$ with $9 \mathrm{df}$, the critical $X^{2}=33.72$ ) (Fig. 1) [23]. Six of the MMSS items were skewed ( $Z$ score of Skewness $\geq \pm 3.29$ ) (Table 1). All the items were retained without transformation inasmuch as a related instrument was found to be valid in German and Portuguese samples [10, 24].

In view of the fact that six item scores were skewed a confirmatory factor analysis (CFA) using maximum likelihood extraction with bootstrapping was carried out.

Table 1 Descriptive statistics of the Mizan meta-memory and meta-concentration scale for students (MMSS) in university students

\begin{tabular}{|c|c|c|c|c|c|c|c|c|c|c|c|c|c|c|c|}
\hline \multirow{2}{*}{$\begin{array}{l}\text { Items } \\
\text { of the } \\
\text { MMSS }\end{array}$} & \multicolumn{2}{|c|}{$\begin{array}{l}\text { Cronbach's Alpha if } \\
\text { Item Deleted }\end{array}$} & \multicolumn{2}{|c|}{$\begin{array}{l}\text { Item-Factor } \\
\text { correlation }\end{array}$} & \multirow[t]{2}{*}{ Mean \pm SD } & \multicolumn{2}{|l|}{ Skewness } & \multicolumn{2}{|l|}{ Kurtosis } & \multicolumn{6}{|c|}{ Percentage distribution across item scores } \\
\hline & $\overline{1-F}$ & $2-\mathrm{F}$ & $\overline{1-F}$ & $2-\mathrm{F}$ & & Statistic(SE) & $z$ & Statistic(SE) & $z$ & 1 & 2 & 3 & 4 & 5 & $\overline{\text { Missing value }}$ \\
\hline BMMS-1 & .81 & & $.75^{*}$ & & $3.44 \pm 1.05$ & $-.57(.12)$ & -4.53 & $-.31(.25)$ & -1.23 & 5.2 & 14.4 & 24.0 & 43.6 & 12.5 & .3 \\
\hline BMMS-2 & .81 & & $.76^{*}$ & & $3.53 \pm 1.10$ & $-.64(.12)$ & -5.13 & $-.33(.25)$ & -1.33 & 5.5 & 14.4 & 18.5 & 43.9 & 17.2 & .5 \\
\hline BMMS-3 & .83 & & $.77^{*}$ & & $3.38 \pm 1.27$ & $-.39(.12)$ & -3.13 & $-.93(.25)$ & -3.73 & 9.9 & 16.2 & 20.1 & 30.5 & 22.2 & 1.0 \\
\hline BMMS-4 & .79 & & $.80^{*}$ & & $3.53 \pm 1.09$ & $-.68(.12)$ & -5.45 & $-.25(.25)$ & -.99 & 5.5 & 13.6 & 18.6 & 45.5 & 16.4 & .5 \\
\hline BMMS-5 & .80 & & $.77^{*}$ & & $3.44 \pm 1.08$ & $-.49(.12)$ & -3.89 & $-.39(.25)$ & -1.58 & 5.5 & 13.8 & 26.4 & 38.6 & 14.9 & .8 \\
\hline BMCS-1 & & .72 & & $.82^{*}$ & $3.35 \pm 1.10$ & $-.50(.12)$ & -3.98 & $-.47(.25)$ & -1.90 & 7.3 & 15.1 & 25.3 & 39.9 & 12.3 & .0 \\
\hline BMCS-2 & & .74 & & $.78^{*}$ & $3.25 \pm 1.03$ & $-.30(.12)$ & -2.43 & $-.48(.25)$ & -1.94 & 5.5 & 18.0 & 31.6 & 35.0 & 9.4 & .5 \\
\hline BMCS-3 & & .79 & & $.75^{*}$ & $3.38 \pm 1.15$ & $-.37(.12)$ & -2.96 & $-.58(.25)$ & -2.35 & 7.3 & 14.1 & 29.0 & 31.1 & 17.8 & .8 \\
\hline BMCS-4 & & .74 & & $.76^{*}$ & $3.41 \pm 1.11$ & $-.47(.12)$ & -3.77 & $-.32(.25)$ & -1.30 & 7.3 & 11.0 & 31.1 & 34.2 & 16.2 & .3 \\
\hline $1-\mathrm{F}$ & & & & & $17.32 \pm 4.39$ & $-.61(.12)$ & -4.90 & $-.06(.25)$ & -.24 & & & & & & \\
\hline $2-\mathrm{F}$ & & & & & $13.39 \pm 3.47$ & $-.38(.12)$ & -3.02 & $-.11(.25)$ & -.43 & & & & & & \\
\hline
\end{tabular}

$D$ Standard deviation, SE Standard Error

BMMS Brief Meta-memory sub-scale, BMCS Brief Meta-concentration sub-scale, BMMS-1 to BMMS-5: items of BMMS, BMCS-1 to BMCS-4: items of BMCS 1-F: Meta-memory subscale; 2-F: Meta-concentration subscale ${ }^{*} p<.01$ 
Modification indices (co-varying error terms) were employed to increase the fit during confirmatory factor analysis (CFA). The standardized loadings of the MMSS item scores on the respective factors were estimated. CFA was used to screen two 2-Factor models; model-A: a 2-Factor model based on theoretical considerations [10], and model-B: a 2-Factor model with incorporation of modification indices (co-varying error terms) (Table 2, Fig. 2). Multiple fit indices from different categories were employed according to recommended norms [23, 25, 26]. Analyses based on discrepancy functions, such as $\chi^{2}, \chi^{2} / \mathrm{df}$ and standardized root mean square residual (SRMR), absolute fit index, the goodness of fit index (GFI), tests comparing target model with the null model (such as the comparative fit index [CFI]), non-centrality indices (such as the root mean square error of approximation [RMSEA]), and PClose were employed [23, 27]. The findings for various tests, e.g., RMSEA $(\leq .08)$, RMR $(\leq 0.05)$ and $\chi^{2} / \mathrm{df}(\leq 3)$ indicated an acceptable fit [28]. For CFI and GFI a value greater than 0.95 implied an excellent fit [28]. A non-zero value of the PClose also indicated an acceptable fit [28]. Tests for evaluation of configural, metric/weak, scalar/strong and strict measurement invariance for the model validated by CFA were performed.

\section{Results}

\section{Participants' characteristics}

Participants' characteristics are shown in Table 3. The mean age was $21.2 \pm 3.4$ years, and students with normal BMI's formed the largest subgroup, making up $66.1 \%$ of the sample (Table 3). Amhara and Oromo ethnicities together comprised the majority (59\%) of the study population (Table 3). The self-reported prevalence of the use of

Table 2 Discriminant or divergent validity: Correlation of the Mizan meta-cognition scale for students (MMSS) scores with Epworth sleepiness scale (ESS) scores in university students

\begin{tabular}{ll}
\hline MMS scores & ESS score \\
\hline BMMS-1 & -.04 \\
BMMS-2 & -.11 \\
BMMS-3 & -.01 \\
BMMS-4 & -.05 \\
BMMS-5 & -.01 \\
BMCS-1 & -.11 \\
BMCS-2 & -.06 \\
BMCS-3 & -.06 \\
BMCS-4 & -.06 \\
Meta-memory & -.07 \\
Meta-concentration & -.11 \\
Total score & -.04 \\
\hline BMMS Bref Meta-memoy sub-scal, BMCS Bief Meta-concentaton sub-sc,
\end{tabular}

BMMS Brief Meta-memory sub-scale, BMCS Brief Meta-concentration sub-scale, BMMS-1 to BMMS-5: items of BMMS, BMCS-1 to BMCS-4: items of BMCS alcohol, Khat and cigarettes were 10.2, 9.9 and 5.7\%, respectively (Table 3 ). Nearly $1 / 10$ th, i.e., $11.5 \%$ of the sample, reported having chronic medical conditions, including AIDS, hepatitis-A, hepatitis-B, hypertension, diabetes mellitus I/II, and tuberculosis (Table 3). It was observed that a high mean MMSS global score of $30.71 \pm 7.29$ occurred in the study population (Table 3 ).

\section{Preliminary item analysis}

The descriptive analysis of the MMSS scores is shown in Table 1 . There were $0-1 \%$ missing values for the MMSS item scores in the final study sample. Little's test $\left[\mathrm{X}^{2}=65.98(\mathrm{df}=62), p<0.34\right]$ indicated that the missing values for MMSS scores were completely random. Missing values were dealt with by adding in the expected maximization because it is a method of choice irrespective of sample size, the proportion of data missing, and distribution characteristics [29]. None of the MMSS item scores showed a floor effect; the lowest score occurred in less than $15 \%$ of the sample [30, 31]. However, five items, i.e., BMMS-2, BMMS-3, BMMS-4, BMCS-3, and BMCS-4 demonstrated a ceiling effect, i.e., the highest scores were achieved by more than $15 \%$ of the respondents [30, 31]. The MMSS global score did not demonstrate any significant problems in terms of ceiling/ floor effects, with $0.5 \%$ reporting the lowest score of 9 and $0.8 \%$ reporting the highest score of 45 . The meta-memory score did not demonstrate any significant problems in terms of ceiling/floor effects, with $1.0 \%$ reporting the lowest score of 5 and $1.8 \%$ reporting the highest score of 25 . The meta-concentration score did not demonstrate any significant problems in terms of ceiling/floor effects, with $0.8 \%$ reporting the lowest score of 4 and $4.7 \%$ reporting the highest score of 20 .

\section{Factor analysis \\ Measures assessing adequacy, suitability and factorability of the MMSS scores}

The diagonal elements of the anti-image correlation matrix of the MMSS item scores were either 0.89 or above, satisfying the condition for factor analysis (Table 4) [32]. The MMSS item scores had an excellent degree of shared variance, as indicated by a Kaiser-Meyer-Olkin Test of sampling adequacy of 0.91 (Table 4) [32]. The MMSS item scores had linear combinations necessary for factor analysis, as suggested by a significant Bartlett's test of sphericity (Table 4) [32]. There was neither an issue of singularity nor of the multicollinearity as required for factor analysis in the MMSS item score, because the determinant of the correlation matrix was greater than 0.00001 and less than 1 (Table 4) [32]. A threshold for variance was derived from the 


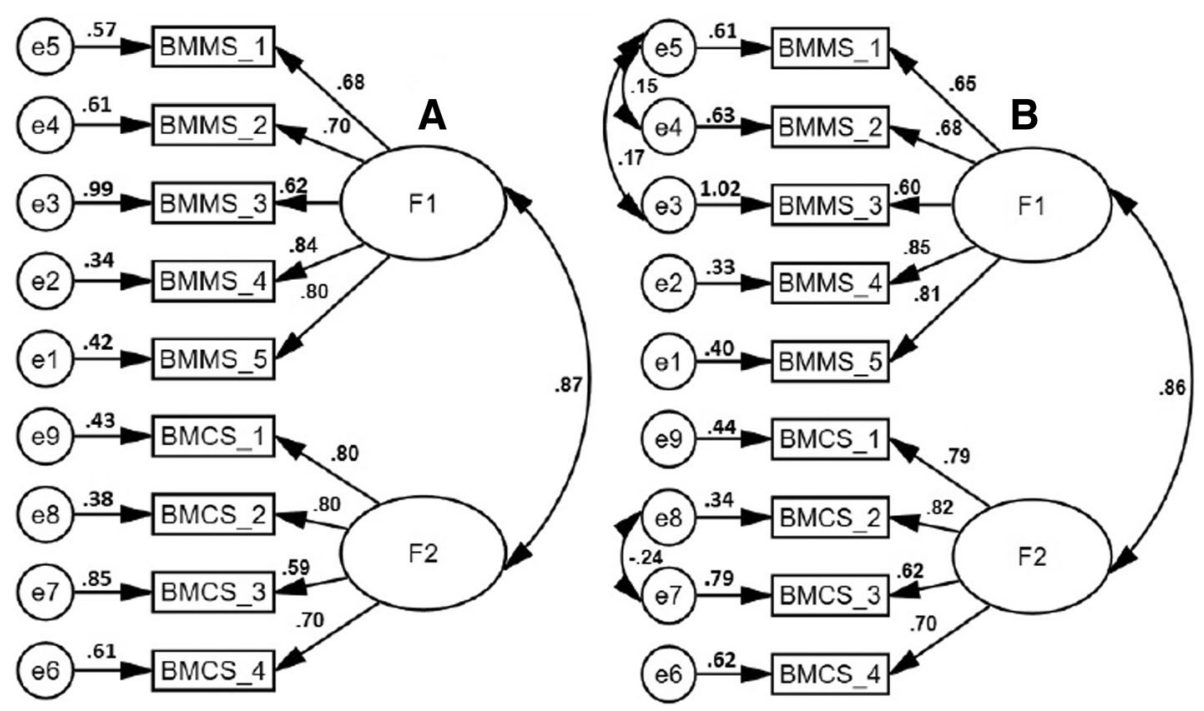

Fig. 2 Confirmatory factor analysis models of the Mizan meta-memory and meta-concentration scale for students (MMSS) in university students. A: 2-Factor, B: 2-Factor model with incorporation of modification indices (correlated error terms). BMMS: Brief Meta-memory sub-scale; BMCS: Brief Meta-concentration sub-scale, bmms_1 to bmms_5: items of BMMS, bmcs_1 to bmcs_4: items of BMCS. All coefficients are standardized. Ovals latent variables, rectangles measured variables, circles error terms, single-headed arrows between ovals and rectangles factor loadings, single-headed arrows between circles and rectangles error terms. Amos does not display standardized values of uniqueness on the models; therefore models were manually edited to put numerical values taken from the Amos text output (Estimates $\rightarrow$ Scalars $\rightarrow$ Variances)

common factors as determined by a range of 0.34 to 0.65 for the communality (Table 4), therefore all the MMSS items were retained for the factor analysis [33]. None of the inter-item correlations were less than 0.3 $(r=0.37-0.71, \quad p<0.01)$, therefore ideal conditions were found for the factorability of the MMSS item score correlation matrix [34] (Table 5).

\section{Confirmatory factor analysis (CFA)}

Table 6 shows the goodness of fit statistics of the models screened in the CFA of the MMSS scores in the university students. Both models had either an excellent or an acceptable fit, i.e., CFI and GFI $>.95$, SRMR and RMSEA $<.08$ and $\mathrm{X}^{2} / \mathrm{df}<3$ and PClose $>0$ [28].

\section{Measurement invariance of model-B among gender groups} The configural invariance of Model-B was excellent as indicated by values of the fit indices $\left(\mathrm{X}^{2} / \mathrm{df}<2\right.$, CFI $>.95$, RMSEA $(\mathrm{CI})<.05$, when groups were estimated without constraints (Table 7). Chi-square testing did not reveal significant differences $\left(\left[\Delta \mathrm{X}^{2}(\mathrm{df})=10.988\right.\right.$ (7), $\left.p=.139\right]$ and $\Delta C F I<.01)$ between the model constrained for loadings and the fully unconstrained model, thus supporting metric or weak invariance of the Model-B, across gender groups (Table 7) [35]. Strong or scalar invariance of model-B was indicated by a finding of non-significance following chi-square testing ( $\left[\Delta \mathrm{X}^{2}(\mathrm{df})=14.234(9), p=.114\right]$ and $\Delta$ CFI $<.01)$ between models constrained for loadings and models constrained for intercepts (Table 7) [35]. Models constrained for residuals and models constrained for intercepts showed significant chi-square differences $\left(\left[\Delta \mathrm{X}^{2}(\mathrm{df})=53.024(15), p<.001\right]\right.$ but $\left.\Delta \mathrm{CFI}<.01\right)($ Table 7$)$ [35].

\section{Internal consistency and homogeneity}

The Cronbach's alpha for the meta-memory and metaconcentration subscales were 0.84 and 0.80 , respectively (Table 8). The McDonald's Omega for the meta-memory and meta-concentration subscales were 0.84 and 0.82 , respectively (Table 8 ). Item-Factor score correlations for the meta-memory subscale ranged between $r=0.75(p<.01)$ and $r=0.80(p<.01)$ (Table 1). Item-Factor score correlations for meta-concentration subscale ranged between $r=0.75 \quad(p<.01)$ and $r=0.82 \quad(p<.01) \quad($ Table 1$)$. Inter-item correlations ranged between $r=0.32(p<.01)$ and $r=0.68(p<.01)$ (Table 5).

\section{Divergent construct validity}

There was no significant correlation between the ESS score and MMSS scores.

\section{Discussion}

This is the first study to carry out a psychometric validation of an instrument for measuring two important aspects of meta-cognition i.e., meta-memory and meta-concentration, in a student population. The study found sufficient psychometric validation of the MMSS to support the conclusion that this instrument measures what it is intended to measure. This was evidenced by the absence of findings of major issues in terms of ceiling/floor effect, favorable item 
Table 3 Participant characteristics

\begin{tabular}{|c|c|}
\hline Characteristics & Mean \pm SD/frequency \\
\hline Age (yr) & $20.97 \pm 1.83$ \\
\hline \multicolumn{2}{|l|}{$\mathrm{BMI}\left(\mathrm{Kg} / \mathrm{m}^{2}\right)$} \\
\hline Underweight & $51(13.3)$ \\
\hline Normal & $253(66.1)$ \\
\hline Over-weight & $19(5.0)$ \\
\hline Obese & $9(2.3)$ \\
\hline Unreported & $51(13.3)$ \\
\hline \multicolumn{2}{|l|}{ Gender } \\
\hline Male & $261(68.1)$ \\
\hline Female & $103(26.9)$ \\
\hline Unreported & $19(5.0)$ \\
\hline \multicolumn{2}{|l|}{ Ethnicity } \\
\hline Amhara & $142(37.1)$ \\
\hline Tigray & $8(2.1)$ \\
\hline Oromo & $84(21.9)$ \\
\hline Keffa & $2(0.5)$ \\
\hline Bench & $3(0.8)$ \\
\hline Others & $49(12.8)$ \\
\hline Unreported & $95(24.8)$ \\
\hline \multicolumn{2}{|l|}{ Substance use } \\
\hline \multicolumn{2}{|l|}{ Alcohol } \\
\hline Yes & $39(10.2)$ \\
\hline No & $339(88.5)$ \\
\hline Unreported & $5(1.3)$ \\
\hline \multicolumn{2}{|l|}{ Khat } \\
\hline Yes & $38(9.9)$ \\
\hline No & $337(88.0)$ \\
\hline Unreported & $8(2.1)$ \\
\hline \multicolumn{2}{|l|}{ Smoking } \\
\hline Yes & $22(5.7)$ \\
\hline No & $356(93.0)$ \\
\hline Unreported & $5(1.3)$ \\
\hline \multicolumn{2}{|l|}{ Tea/Coffee } \\
\hline Yes & $343(89.6)$ \\
\hline No & $40(10.4)$ \\
\hline \multicolumn{2}{|c|}{ Other beverages } \\
\hline Yes & $254(66.1)$ \\
\hline No & $99(25.8)$ \\
\hline Unreported & $30(7.8)$ \\
\hline ESS & $6.9 \pm 4.7$ \\
\hline
\end{tabular}

Table 3 Participant characteristics (Continued)

\begin{tabular}{ll}
\hline Characteristics & Mean \pm SD/frequency \\
\hline Presence of Chronic conditions & \\
No & $215(56.1)$ \\
Yes & $44(11.5)$ \\
Unreported & $124(32.4)$ \\
MMSS global score & $30.71 \pm 7.29$
\end{tabular}

$S D$ standard deviation, ESS Epworth sleepiness scale

Chronic health conditions like AIDS, Hepatitis-A, Hepatitis-B, Hypertension

Diabetes Mellitus I/II, Tuberculosis, others

MMSS Mizan meta-memory and meta-concentration scale for students

discrimination, factorial validity and measurement invariance across gender groups, internal consistency, and divergent validity.

\section{Preliminary item analysis}

There was some concern about the ceiling effect in five item scores of the MMSS; the presence of this phenomenon could possibly affect the responsiveness and discriminative validity of this instrument for the highest score of these items [30]. The MMSS items are scored in such a way that normal behavior, i.e., of metacognitive functioning, is indicated by higher scores, therefore, the presence of the ceiling effect is possibly explained by the non-clinical nature of the study population. Indeed, a scale for assessing affective disorders, i.e., the Hospital Anxiety and Depression Scale (HADS) was reported to show a floor effect when validated in a normal elderly Swedish population [36]. This situation is similar to the one we encountered for the MMSS, because in the case of the HADS, the lower score denotes normal behavior, while for the MMSS it is the higher score [36]. However, the absence of the ceiling/floor effect in the MMSS global score and factor scores, as well as the absence of the floor effect for all the MMSS item scores, are further evidence of its applicability in student populations [36]. Additionally, findings which were similar to our own with respect to the ceiling/floor effect were confirmed for the brief Meta-Cognition Questionnaire, of which the MMSS is an adapted version, thus providing concurrent evidence for the presently studied instrument's overall validity [10, 24]. The Cronbach's alpha if item deleted (all above 0.72) and

Table 4 Sample size adequacy measures of the Mizan metacognition scale for students (MMSS) in university students

\begin{tabular}{ll}
\hline Measures & Values \\
\hline Anti-image matrix & $0.89-0.94$ \\
Bartlett's test of Sphericity & $X^{2}(\mathrm{df}=36), p<0.001$ \\
Determinant & 0.016 \\
Kaiser-Meyer-Olkin Test of & 0.91 \\
Sampling Adequacy (KMO) & \\
Communality & $0.34-0.65$ \\
\hline
\end{tabular}


Table 5 Inter-item Correlation matrix of the Mizan meta-memory and meta-concentration scale for students (MMSS) in university students

\begin{tabular}{|c|c|c|c|c|c|c|c|c|c|}
\hline & BMMS-1 & BMMS-2 & BMMS-3 & BMMS-4 & BMMS-5 & BMCS -1 & BMCS -2 & BMCS -3 & BMCS -4 \\
\hline BMMS-1 & & $.51^{*}$ & $.49^{*}$ & $.52^{*}$ & $.46^{*}$ & $.43^{*}$ & $.42^{*}$ & $.42^{*}$ & $.32^{*}$ \\
\hline BMMS-2 & & & $.44^{*}$ & $.56^{*}$ & $.53^{*}$ & $.46^{*}$ & $.45^{*}$ & $.41^{*}$ & $.42^{*}$ \\
\hline BMMS-3 & & & & $.49^{*}$ & $.46^{*}$ & $.42^{*}$ & $.35^{*}$ & $.45^{*}$ & $.32^{*}$ \\
\hline BMMS-4 & & & & & $.68^{*}$ & $.55^{*}$ & $.56^{*}$ & $.39^{*}$ & $.47^{*}$ \\
\hline BMMS-5 & & & & & & $.47^{*}$ & $.57^{*}$ & $.37^{*}$ & $.52^{*}$ \\
\hline BMCS-1 & & & & & & & $.62^{*}$ & $.50^{*}$ & $.49^{*}$ \\
\hline BMCS-2 & & & & & & & & $.38^{*}$ & $.53^{*}$ \\
\hline BMCS-3 & & & & & & & & & $.44^{*}$ \\
\hline BMCS-4 & & & & & & & & & \\
\hline
\end{tabular}

item-Factor correlations (all above 0.75) indicate that the all items scores of the MMSS had favorable ability to discriminate between low and high scorers [37].

\section{Factor analysis}

Though it is desirable to perform both exploratory factor analysis (EFA) and CFA for establishing factorial validity, it is also an acceptable practice to present findings from CFA for constructs based on theoretical considerations $[10,38]$. Therefore, we employed CFA along with measurement invariance analysis across gender groups to evaluate the validity of the 2-Factor model of the MMSS.

\section{Measures assessing adequacy, suitability and factorability of the MMSS scores}

Factor analysis was employed to investigate the scale's dimensionality because the MMSS scores satisfied the conditions of sample adequacy, sample suitability, and factorability. Evidence for this conclusion came from findings such as the diagonal elements of the correlation anti-image matrix, Bartlett's test of Sphericity, determinant, Kaiser-Meyer-Olkin Test of sampling adequacy (KMO), communality and inter-item correlations, all of which were within normal limits [32].

\section{Confirmatory factor analysis (CFA)}

CFA was employed to establish the dimensionality conditions, though the instrument was expected to produce a 2-Factor model based on theoretical considerations [10]. Both models, i.e., the model-A, a2-Factor model and model-B, a 2-Factor model with incorporation of modification indices (correlated error terms) performed very similarly with excellent to acceptable values for the fit indices [28]. However, model-B was favored because of the higher value of the PClose and lower value of $\chi^{2} / \mathrm{df}$. Furthermore, the very good to excellent level of correlations between the MMSS item scores and its factors for the model-B favor its validity [39].

\section{Measurement invariance of model-B among gender groups} Gender specific differences in metacognitive abilities are common in adolescents [40]. Moreover, gender dependent relationships between metacognitive dysfunctions and affective conditions such as anxiety and depression are also found among adults [41]. Given this background, it was imperative to assess that the MMSS construct comparability is not confounded by gender. Therefore, measurement invariance of the MMSS across gender groups was evaluated in the study population. The validity of the model- $\mathrm{B}$, a 2-Factor model with incorporation of error terms was further evidenced by the establishment of its measurement invariance, i.e., configural, metric, scalar and strict invariance among two gender groups. For metric and scalar invariance, conditions for both, i.e., non-significant differences were found following chi-square testing and $\Delta \mathrm{CFI}<.01$ were met [35]. Even though the chi-square test of difference was significant the finding that $\Delta C F I<.01$ still supports the strict invariance condition [35]. This is because $\triangle C F I$ is a more robust measure than chisquare test of difference [35].

Table 6 Fit statistics of the Mizan meta-memory and meta-concentration scale for students (MMSS) models in university students

\begin{tabular}{|c|c|c|c|c|c|c|c|c|c|}
\hline Models & CFI & GFI & SRMR & RMSEA & $x^{2}$ & df & $p$ & $x^{2} / d f$ & PClose \\
\hline $\bar{A}$ & .97 & .95 & .04 & $.07(.05-.09)$ & 77.95 & 26 & $<.001$ & 3.00 & .02 \\
\hline B & .98 & .97 & .03 & $.06(.03-.08)$ & 49.72 & 23 & .001 & 2.16 & .31 \\
\hline
\end{tabular}

A: 2-Factor, B: 2-Factor model with incorporation of modification indices (correlated error terms)

CFI Comparative Fit Index, GFI Goodness of fit index, SRMR Standardized root mean square residual, RMSEA root mean square error of approximation 
Table 7 Measurement invariance of the 2-Factor model among gender groups of the Mizan meta-memory and meta-concentration scale for students (MMSS) in university students

\begin{tabular}{|c|c|c|c|c|c|c|c|c|c|c|}
\hline & \multirow[t]{2}{*}{$x^{2}$} & \multirow[t]{2}{*}{ df } & \multirow[t]{2}{*}{$P$ value } & \multirow[t]{2}{*}{$x^{2} / d f$} & \multirow[t]{2}{*}{$\mathrm{CFI}$} & \multirow[t]{2}{*}{ RMSEA } & \multicolumn{3}{|c|}{$X^{2}$ difference test statistics } & \multirow[t]{2}{*}{$\Delta C F I$} \\
\hline & & & & & & & $\overline{\Delta X^{2}}$ & $\Delta \mathrm{df}$ & $P$ value & \\
\hline \multicolumn{11}{|l|}{ 2-Factor model: MMSS } \\
\hline Equal form & 82.868 & 46 & .001 & 1.801 & .977 & .047 & & & & \\
\hline Metric invariance-Equal loadings & 93.856 & 53 & .000 & 1.771 & .974 & .046 & 10.988 & 7 & .139 & -.001 \\
\hline Scalar invariance-Equal intercepts & 108.091 & 62 & .000 & 1.743 & .971 & .046 & 14.234 & 9 & .114 & .000 \\
\hline Strict invariance-Equal factor variances & 161.115 & 77 & .000 & 2.092 & .947 & .055 & 53.024 & 15 & .000 & +.009 \\
\hline
\end{tabular}

\section{Internal consistency and homogeneity}

According to the "rule of thumb" of [42] George and Mallery (2003), the MMSS and its subscale internal consistency were good, as implied by the Cronbach's alpha and Mcdonald's omega [42]. Furthermore, according to the criteria of Nunnaly and Bernstein, the Cronbach's alpha of the factors of the MMSS suggest that it may have a potentially viable application in experimental research as well [22]. The Cronbach's alpha of the MMSS was higher than that reported for the related instrument in a German elderly population $(0.61-0.67)$ [10]. The internal homogeneity of the MMSS was supported by the strong item-total correlations in this student population. Here again, the item-total correlations were higher for the MMSS than that of the brief meta-cognition questionnaire in the German population $(r=0.26-0.52)$ [10]. Inter-item correlations indicated a moderate to a strong relationship, thus reinforcing the internal homogeneity of the MMSS in the study population.

\section{Divergent construct validity}

Daytime sleepiness is an important defining feature of insomnia [43]. Furthermore, metacognition is associated with mental activity in primary insomnia [39, 40]. Therefore, ESS, which is a measure of sleepiness, was employed to assess the divergent validity of the MMSS. No correlation between the MMSS scores and the self-reported measure of daytime sleepiness support the divergent construct validity of the scale in the study population. This is because even though sleepiness and sleep are associated with meta-cognition in some populations but these represent non-overlapping constructs [44, 45]. In summary, the present findings of an absence of ceiling/floor effect for the MMSS global and factor scores, sufficient item

Table 8 Internal consistency: Cronbach's alpha and McDonald's Omega of the 2-Factor model of the Mizan meta-memory and meta-concentration scale for students (MMSS) in Ethiopian university students

\begin{tabular}{lll}
\hline & Cronbach's alpha & McDonald's Omega \\
\hline Meta-memory & 0.84 & 0.84 \\
Meta-concentration & 0.80 & 0.82 \\
\hline
\end{tabular}

discrimination, factorial validity, measurement invariance across gender groups for the factor structure of the MMSS, good internal consistency, strong internal homogeneity, and sufficient divergent validity favored psychometric validation of the MMSS in university students.

Some of the limitations of the study were that assessments of test-retest reliability, convergent validity, and concurrent validity were not carried out. The sample had a biased gender ratio. Therefore, the generalizations are more likely to be applicable for male students, who outnumbered females in the present study. Even though simple random sampling was used, fewer females completed the study, thereby causing the gender representation to be unbalanced. Future efforts to investigate the psychometric properties of the MMSS should accordingly anticipate and plan for a higher drop-out rate among female students, which could occur at any time from the stage of enrollment to the completion of the study. The scale was designed to assess to two important dimensions of the metacognition, i.e., meta-memory and meta-concentration. Future work should build on the current findings to incorporate brief subscales for other dimensions of metacognition to get a comprehensive yet brief tool to assess this function in students.

\section{Conclusion}

Despite these qualifications, the findings of the present study are generally supportive of the value and applicability of this instrument. The MMSS, which is the first measure of meta-memory and meta-concentration to be evaluated in a sample of university students, thus has relevance for use in student populations. This conclusion is supported by psychometric measures of its ceiling/floor effect, internal consistency, internal homogeneity, divergent validity, factorial validity and measurement invariance of the validated factor structure across gender groups.

\section{Additional file}

Additional file 1: Appendix I contains the Mizan meta-memory and meta-concentration scale for students (MMSS) and its scoring guideline. (DOCX $14 \mathrm{~kb})$ 


\section{Abbreviations}

CFA: Confirmatory factor analysis; CFI: Comparative Fit Index; ESS: Epworth sleepiness scale; GFI: Goodness of fit index; HADS: Hospital Anxiety and Depression Scale; KMO: Kaiser-Meyer-Olkin Test of Sampling Adequacy: MCQ: Metacognition Questionnaire; MIA: Metamemory in Adulthood; MMSS: Mizan meta-memory and meta-concentration scale for students; RMSEA: Root mean square error of approximation; SRMR: Standardized root mean square residual

\section{Acknowledgements}

We are grateful to the participants of the study. The authors would like to thank Deanship of Scientific Research at Majmaah University for supporting this work.

\section{Clinical trials registry site and number}

Not applicable.

\section{Funding}

No funding was received for this study.

\section{Availability of data and materials}

The datasets used and/or analysed during the current study are available from the corresponding author on reasonable request.

\section{Authors' contributions}

MDM, DWS, AA, SRP: concept development and study design; MS, PS: data acquisition; MDM: analysis and interpretation, manuscript preparation; MDM, MS, PS, DWS, AA, SRP: critical revision of the manuscript, and All authors read and approved the final version of the manuscript.

\section{Ethics approval and consent to participate}

The study was approved by the Human Institutional Ethics Committee, Mizan-Tepi University, and informed written consent was obtained from all participants. All authors have approved the final draft.

\section{Consent for publication}

The participants provided informed written consent to publish though no personal and/or identifiable information has been published.

\section{Competing interests}

All the authors declare that they have no competing interests.

\section{Publisher's Note}

Springer Nature remains neutral with regard to jurisdictional claims in published maps and institutional affiliations.

\section{Author details}

'Department of Nursing, College of Applied Medical Sciences, Majmaah University, Al Majmaah 11952, Saudi Arabia. ${ }^{2}$ Department of Pharmacy, College of Medicine and Health Sciences, Mizan-Tepi University (Mizan Campus), Mizan-Aman, Ethiopia. ${ }^{3}$ Department of Biomedical Sciences, College of Medicine and Health Sciences, Mizan-Tepi University (Mizan Campus), Mizan-Aman, Ethiopia. ${ }^{4}$ Independent researcher, 652 Dufferin Street, Toronto, ON M6K 2B4, Canada. ${ }^{5}$ Somnogen Canada Inc, College Street, Toronto, ON, Canada.

Received: 28 August 2018 Accepted: 5 December 2018 Published online: 18 December 2018

\section{References}

1. Zohar A, Barzilai S. A review of research on metacognition in science education: current and future directions. Stud Sci Educ. 2013;49(2):121-69.

2. John H Flavell LR: Social cognitive development: Frontiers and possible futures, paperback edn. New York, NY: Cambridge University Press; 1981

3. Semerari A, Cucchi M, Dimaggio G, Cavadini D, Carcione A, Battelli V, Nicolo G, Pedone R, Siccardi T, D'Angerio S et al: The development of the Metacognition Assessment interview: instrument description, factor structure and reliability in a non-clinical sample. Psychiatry Res. 2012;200(2-3):890-95.

4. Ladegaard N, Lysaker PH, Larsen ER, Videbech P: A comparison of capacities for social cognition and metacognition in first episode and prolonged depression. Psychiatry Res. 2014;220(3):883-9.
5. Melli G, Carraresi C, Poli A, Bailey R. The role of metacognitive beliefs in health anxiety. Personal Individ Differ. 2016;89:80-5.

6. Hsieh YHHC, Liu CY, Huang TL. The levels of stress and depression among interns and clerks in three medical centers in Taiwan-a cross-sectional study. Chang Gung Med J. 2011;34(3):278-85.

7. Lemma S, Gelaye B, Berhane Y, Worku A, Williams MA. Sleep quality and its psychological correlates among university students in Ethiopia: a crosssectional study. BMC Psychiatry. 2012;12:237.

8. Gebreslassie M, Feleke A, Melese T. Psychoactive substances use and associated factors among Axum university students, Axum town, North Ethiopia. BMC Public Health. 2013;13:693.

9. Lachman ME, Andreoletti C, Pearman A. Memory control beliefs: how are they related to age, strategy use and memory improvement? Soc Cogn. 2006;24(3):359-85.

10. Klusmann V, Evers A, Schwarzer R, Heuser I. A brief questionnaire on metacognition: psychometric properties. Aging Ment Health. 2011;15(8): 1052-62.

11. Dunlosky J, Metcalfe J. Metacognition. Thousand oaks, California: SAGE publications, Inc; 2008

12. Lockl K, Schneider W. Precursors of metamemory in young children: the role of theory of mind and metacognitive vocabulary. Metacognition and Learning. 2006;1(1):15-31.

13. Zemira R, Mevarech CA. Immediate and delayed effects of meta-cognitive instruction on regulation of cognition and mathematics achievement. Metacognition and Learning. 2008;3(2):147-57.

14. Schwartz BL, Efklides A. Metamemory and memory efficiency: implications for student learning. J. Appl. Res. Mem. Cogn. 2012;1(3):145-51.

15. Richardson M, Abraham C, Bond R: Psychological correlates of university students' academic performance: a systematic review and meta-analysis. Psychol Bull. 2012;138(2):353-87.

16. Dixon RA, Hultsch DF, Hertzog C. The Metamemory in adulthood (MIA) questionnaire. Psychopharmacol Bull. 1988;24(4):671-88.

17. Wells A, Cartwright-Hatton S. A short form of the metacognitions questionnaire: properties of the MCQ-30. Behav Res Ther. 2004;42(4): 385-96.

18. Prince MJ, Reischies F, Beekman AT, Fuhrer R, Jonker C, Kivela SL, Lawlor BA, Lobo A, Magnusson H, Fichter M, van Oyen H, Roelands M, Skoog I, Turrina C, Copeland JR. Development of the EURO-D scale-a European, union initiative to compare symptoms of depression in 14 European centres. $\mathrm{Br}$ J Psychiatry. 1999;174:330-8.

19. Johns MW. A new method for measuring daytime sleepiness: the Epworth sleepiness scale. Sleep. 1991;14(6):540-5.

20. Gaskin J LJ: Model Fit Measures, AMOS Plugin. In.; 2016.

21. Gasking J, Lim, J. : Master validity tool. AMOS Plugin In: Gaskination's StatWiki; 2016a.

22. Nunnally JC, Bernstein IH. Psychometric theory. 3rd ed. New York: McGrawHill; 1994.

23. Jaccard J, Wan CK. LISREL approaches to interaction effects in multiple regression: Sage Publications; 1996

24. França $A B$, Schelini PW. Análise semântica e evidências de validade da escala metacognitiva para idosos. Aval Psicol. 2014;13(3):333-41.

25. Manzar MD, Zannat W, Moiz JA, Spence DW, Pandi-Perumal SR, Bahammam AS, Hussain ME. Factor scoring models of the Pittsburgh sleep quality index: a comparative confirmatory factor analysis. Biol Rhythm Res. 2016;47(6):851-64.

26. Manzar MD, Zannat W, Hussain ME, Pandi-Perumal SR, Bahammam AS, Barakat D, Ojike NI, Olaish A, Spence DW. Dimensionality of the Pittsburgh sleep quality index in the young collegiate adults. Springerplus. 2016;5(1): 1550. https://doi.org/10.1186/s40064-016-3234-x:\%202016a.

27. Jaccard J, Wan CK. LISREL Approaches to Interaction Effects in Multiple Regression, vol. 114. 1st ed. Thousand Oaks, California: SAGE Publications, Inc; 1996.

28. Hu LT, Bentler PM. Cutoff criteria for fit indexes in covariance structure analysis: conventional criteria versus new alternatives. Struct Equ Model Multidiscip J. 1999:6(1):1-55.

29. Gold MS, Bentler PM. Treatments of missing data: a Monte Carlo comparison of RBHDI, iterative stochastic regression imputation, and expectation-maximization. Struct Equ Model Multidiscip J. 2000;7(3): 319-55.

30. Lim CR, Harris K, Dawson J, Beard DJ, Fitzpatrick R, Price AJ. Floor and ceiling effects in the OHS: an analysis of the NHS PROMs data set. BMJ Open. 2015;5(7):e007765. 
31. Salahuddin M, Maru TT, Kumalo A, Pandi-Perumal SR, Bahammam AS, Manzar MD: Validation of the Pittsburgh sleep quality index in community dwelling Ethiopian adults. Health Qual Life Outcomes. 2017;15(1):58.

32. Field A: Discovering statistics using IBM SPSS statistics, Fourth edn; 2013.

33. Costello AB, Osborne JW. Best practices in exploratory factor analysis: four recommendations for getting the Most from your analysis. Pract Assess Res Eval. 2005;10(7):1-9.

34. Tabachnick BG, Fidell LS. Using multivariate statistics. fifth ed. Boston, MA: Allyn \& Bacon/Pearson Education; 2007.

35. Cheung GW, Rensvold RB. Evaluating goodness-of-fit indexes for testing measurement invariance. Struct Equ Model Multidiscip J. 2002;9(2):233-55.

36. Djukanovic ICJ, Årestedt K. Is the hospital anxiety and depression scale (HADS) a valid measure in a general population 65-80 years old? A psychometric evaluation study. Health Qual Life Outcomes. 2017;15(1):193.

37. Wang M, Batt K, Kessler C, Neff A, Iyer NN, Cooper DL, Kempton CL. Internal consistency and item-total correlation of patient-reported outcome instruments and hemophilia joint health score v2.1 in US adult people with hemophilia: results from the pain, functional impairment, and quality of life (P-FiQ) study. Patient Prefer Adherence. 2017;11:1831-9.

38. Manzar MD, BaHammam AS, Hameed UA, Spence DW, Pandi-Perumal SR, Moscovitch A, Streiner DL. Dimensionality of the Pittsburgh Sleep Quality Index: a systematic review. Health Qual Life Outcomes. 2018;16(1):89.

39. Comrey AL, Lee HB. A first course in factor analysis. Second ed. Hillsdale, NJ: Lawrence Erlbaum Associates, Inc; 1992.

40. Liliana C, Lavinia H. Gender differences in metacognitive skills. A study of the 8th grade pupils in Romania. Procedia Soc Behav Sci. 2011;29:396-401.

41. Lenzo VTM, Tripodi F, Quattropani MC. Gender differences in anxiety, depression and metacognition. The European Proceedings of Social \& Behavioural Sciences. 2016;9:1-6.

42. Darren G, Mallery P. SPSS for Windows Step by Step: A Simple Guide and Reference, 11.0 Update. Boston: Allyn and Bacon; 2003.

43. Medicine AAoS. International classification of sleep disorders, 3rd ed. edn. Darien: American Academy of Sleep Medicine; 2014.

44. Palagini L, Piarulli A, Menicucci D, Cheli E, Lai E, Bergamasco M, Mauri M, Kyle SD, Espie CA, Gemignani A: Metacognitive beliefs relate specifically to sleep quality in primary insomnia: a pilot study. Sleep Med. 2014;15(8):918-22.

45. Cohen-Zion M, Shiloh E: Evening chronotype and sleepiness predict impairment in executive abilities and academic performance of adolescents. Chronobiol Int. 2018;35(1):137-45.

Ready to submit your research? Choose BMC and benefit from:

- fast, convenient online submission

- thorough peer review by experienced researchers in your field

- rapid publication on acceptance

- support for research data, including large and complex data types

- gold Open Access which fosters wider collaboration and increased citations

- maximum visibility for your research: over $100 \mathrm{M}$ website views per year

At BMC, research is always in progress.

Learn more biomedcentral.com/submissions 